\title{
IGF System in Cancer
}

\author{
S. John Weroha and Paul Haluska \\ Department of Oncology, Mayo Clinic College of Medicine, Rochester, MN 55905
}

\section{IGF System and Cancer Risk}

Insulin-like growth factor (IGF) plays an important role in tissue growth and development. As such, several studies have demonstrated the association between circulating levels of IGF-1 and -II and cancer risk. In patients with acromegaly, an endocrine disorder which is characterized by a hypersecretion of growth hormone $(\mathrm{GH})$ and consequently higher endogenous IGF, several studies have shown a 2-fold increased risk of gastrointestinal cancers [1-4]. Other studies have shown a modest association between higher circulating IGF-1 and -2 levels and an increased risk for prostate, breast, colorectal, and ovarian cancer [5-11]. However, several other studies do not show a similar increase in cancer risk [12-19]. Exogenous recombinant $\mathrm{GH}$ has been proposed as a potential cancer-promoting agent but no convincing link between cancer risk and its use in children or adults have been identified $[20,21]$. The role of IGF in cancer risk is multifactorial and taken together, the preponderance of data suggests a slight increased risk of some cancers due to higher activity of the IGF system. Conversely, patients with congenital deficiencies in IGF-1 have a protective effect against developing cancer [22].

\section{The IGF System in Cellular Proliferation and Survival}

The lifecycle of a normal human cell is tightly regulated by intra- and extracellular signals, working in concert to appropriately control cellular proliferation, senescence, and apoptosis. When the sum of growth stimulatory and inhibitory signals favors proliferation, the cell enters mitosis. For example, circulating IGF-1 and IGF-2 bind to the IGF-1 receptor (IGF-1R) and trigger a signal transduction cascade that leads to increased proliferation and enhanced survival of IGF-responsive cells (Figure 1). Such signaling is central to the processes of oncogenesis. The mitogenic activity of the IGF-1R is mediated through the Ras and AKT pathways and results in the upregulation of cyclin D1 and its binding partner $\mathrm{CDK} 4$, leading to the phosphorylation of retinoblastoma protein, release of E2F transcription factor, and expression of downstream target genes like cyclin E [23, 24]. Moreover, IGF-1R activation downregulates cell cycle suppressors $\mathrm{p} 27^{\mathrm{kip} 1}$, $\mathrm{p} 57^{\mathrm{kip} 2}$, and PTEN [25, 26], indicating multiple pathways are involved.

\footnotetext{
(c) 2012 Elsevier Inc. All rights reserved.

Correspondence should be addressed to: Dr. Paul Haluska, MD, PhD, Division of Medical Oncology, Mayo Clinic College of Medicine, 200 First St. SW, Rochester, MN 55905, haluska.paul@ mayo.edu.

Authors' Disclosure of Potential Conflicts of Interests:

P.H. receives research funds from BMS, Roche, ImClone, GSK, Pfizer, Merck and MedImmune and is an unpaid consultant for BMS, Roche, Merck and MedImmune.

Publisher's Disclaimer: This is a PDF file of an unedited manuscript that has been accepted for publication. As a service to our customers we are providing this early version of the manuscript. The manuscript will undergo copyediting, typesetting, and review of the resulting proof before it is published in its final citable form. Please note that during the production process errors may be discovered which could affect the content, and all legal disclaimers that apply to the journal pertain.
} 
In addition to promoting cellular proliferation, the IGF system is a potent pro-survival stimulus. Apoptosis is the essential process of programed cell death by which normal embryonic tissue architecture is formed and adult tissues are maintained following cellular senescence, injury, and hyperplasia. In adults, apoptosis is responsible for the elimination of senescent mammary epithelial cells during postmenopausal breast tissue involution [27], cardiac remodeling seen in ischemic cardiomyopathy [28], and the removal of excess lobular epithelial cells following periodic breast hyperplasia associated with menstruation [27]. However, cancer cells can often evade the normal apoptosis mechanisms and thus evade programmed cell death. The AKT pathway plays a critical role in apoptosis by inhibiting pro-apoptotic proteins like BAD [29] and FKHR [30] and activating anti-apoptotic factors such as NF-kappa B [31] and MDM2 [32]. The importance of AKT in cancer-related IGF signaling is further exemplified by its role in invasion and metastasis [33]. Taken together, the IGF-1R provides a growth advantage to IGF responsive cells by the promotion of cellular proliferation and enhanced survival.

\section{The Insulin Receptor and Hybrid Receptors}

The insulin receptor (IR) is a tetrameric receptor consisting of two extracellular alpha and two intracellular beta subunits with significant over-all homology to the IGF-1R and $84 \%$ homology at tyrosine kinase domains [34]. The identification of two isoforms generated from the alternative splicing (IR-A) of the full-length transcript (IR-B) results in a 12-amino difference between the two isoforms [35] and differential expression during mammalian development. IR-B is the classic form of the IR which is primarily expressed in liver, muscle, and adipose tissues. It only binds insulin at physiologic concentrations with predominantly metabolic effects $[36,37]$. On the other hand, IR-A is expressed during fetal development and in cancer cells with the ability to bind insulin as well as IGF-2, resulting in metabolic and mitogenic effects, respectively [36]. Breast and ovarian tumor cells have higher IR expression relative to normal epithelial cells [38, 39] and patients with very high IR expression have worse disease free survival [40].

The significant sequence homology has important implications for IGF-1R function in general, and oncogenesis in particular. The discovery that some cancers, such as thyroid, breast, and colon cancer, exhibit a higher relative abundance of IR-A compared to normal cells provided insight into the intimate association between the insulin and IGF systems [36, $41,42]$. Indeed, the homology between IR and IGF-1R permit the formation hybrid receptors (Hybrid-Rs), comprised of one alpha/beta monomer of IR and one of IGF-1R, with the hybrid receptor ligand specificity determined by the IR isoform [43]. For example, heterodimerization of IGF-1R with IR-A or IR-B gives rise to Hybrid-RA or Hybrid-RB, respectively. Both receptor hybrids have affinity for IGF-1 and IGF-2, (and to a lesser extent, insulin for Hybrid-RA) to activate downstream targets leading to cellular proliferation $[44,45]$.

The precise role of Hybrid-Rs in oncogenesis is under active investigation. Hybrid-Rs may increase the functional pool of receptors capable of activating the IGF system and provide further growth advantages to a subset of cells over-expressing IGF-1R, IR-A, or both. Hybrid-Rs also have therapeutic implications since novel therapies targeted against the IGF-1R may have lower efficacy in cancers signaling through IR-A or Hybrid-RA receptors, especially those with a high Hybrid-R:IGF-1R ratio [46]. Furthermore, hyperinsulinemic states may directly stimulate IR-A or Hybrid-RA expression and increase the bioavailability of IGF-1[14, 47]. The role of Hybrid-Rs and IR isoforms in breast and other cancers is an active area of investigation. 


\section{Signal Transduction Crosstalk}

Signaling crosstalk is characterized by the influence of one receptor/signaling system on a separate receptor/signaling system. There is growing evidence that such crosstalk in cancer cells has important implications in the efficacy of novel therapeutics. One such crosstalk pathway occurs between IGF-1R and the erbB family of receptors, which include erbB1 (EGFR) and erbB2 (HER2/neu) (Figure 2). Treatment of breast and ovarian cancer cells with the duel IGF-1R/IR tyrosine kinase inhibitor (TKI) BMS-536924 caused a reciprocal upregulation of the erbB family of receptors which conferred resistance to IGF-1R inhibition [48]. Conversely, treatment of EGFR-dependent, tamoxifen-resistant breast cancer cells with the EGFR-selective TKI gefitinib led to activated IGF-1R signaling and subsequent resistance to EGFR inhibition [49]. Similarly, trastuzumab, a monoclonal antibody that binds HER2, is used to treat HER2-positive breast cancer but resistance is problematic [50] and in vitro studies with SKBR3 breast cancer cells implicate activated IGF-1R in this process [51], which is reversed by inhibition of IGF-1R [52]. One mechanism of resistance to IGF-1R or erbB targeted therapy occurs by the heterodimerization of IGF-1R with erbB receptors [52,53], which provides an alternative signaling pathway to activate downstream mediators of cell proliferation and survival (Figure 2). Another example of crosstalk involves the estrogen receptor (ER), which is an important therapeutic target in adjuvant breast cancer treatment. The IGF-1R may contribute to tamoxifen resistance by two possible mechanisms: 1) IGF-mediated activation of AKT and subsequent estrogen-independent activation of ER [54] or 2) a direct interaction between ER and IGF-1R [55]. An emerging body of evidence supports an additional layer of crosstalk involving mammalian target of rapamycin (mTOR), a downstream effector of AKT with effects on cell proliferation, survival, and angiogenesis. The interaction of mTOR with either Raptor or Rictor results in the formation of functionally-distinct mTOR complex 1 (mTORC1) or 2 (mTORC2), respectively. Activation of mTORC1 leads to S6K1-mediated destabilization of insulin receptor substrate 1 (IRS1) and subsequent inhibition of IR and IGF-1R signaling [56], providing a negative feedback loop to downregulate AKT (Figure 1). Conversely, activation of mTORC2, leads to the upregulation of AKT by the specific phosphorylation of serine 473 [57]. This IGF-1R/AKT/mTOR signaling crosstalk has important therapeutic implications since rapalogs such as sirolimus, temsirolimus, everolimus, and ridaforolimus preferentially inhibit mTORC1 and can promote AKT activation by increased mTORC2 activation in addition to a loss of feedback inhibition [58].

The aforementioned examples of reciprocal crosstalk underscore the complexity of the IGF system in cancer and the need for multi-pathway targeting. Indeed, concomitant treatment of ovarian cancer cells with BMS-536924 and BMS-599626, a pan-HER inhibitor, demonstrated synergistic anti-proliferative activity [48]. Duel therapy is currently being investigated in clinical trials with IMC-A12 (anti-IGF-IR antibody) and cetuximab(antiEGFR antibody) in patients with head and neck cancer and IMC-A12 and lapatinib (tyrosine kinase inhibitor against HER2) in breast cancer[59]. Although a recent clinical trial investigating IMC-A12 and cetuximab in colorectal cancer patients did not show a benefit with IGF-1R inhibition [60], study patients were resistant to prior anti-EGFR therapy and staining for activated AKT, a marker of EGFR and IGF-1R signaling, did not correlate with outcome. With respect to mTOR/IGF-1R duel targeted therapy, early results from a phase I clinical trial evaluating ridaforolimus (small molecule inhibitor of MTOR) and the IGF-1R antibody dalotozumab demonstrates clinical benefit in $16.1 \%$ of patients with advanced cancer and $21.7 \%$ of breast cancer patient [61]. These data suggest multiple pathways are interconnected and support the argument for customized cancer therapy based on pathway activation rather than histologic diagnosis alone. 


\section{IGF Binding Proteins}

There are six IGF binding proteins (IGFBPs) with high affinity for IGF-1 and IGF-2. Serum concentrations of IGF are affected primarily by IGFBP3, which is the most abundant binding protein with the highest affinity for IGF-1 and IGF-2 [62]. Although IGFBPs are synthesized primarily in the liver, many normal and malignant tissues such as lung, breast, and ovarian cancers express IGFBPs [63-65]. These molecules are thought to influence malignancy by several mechanisms. They regulate bioavailability and half-life of IGF-1/2 in the circulation, and provide a mechanism for transport to target organs. IGFBPs also modulate the activity of IGF through important interactions with extracellular proteases that degrade IGFBPs, resulting in the release of ligand and subsequent activation of IGF-1R. These proteolytic fragments, particularly of IGFBP-5 and -3 , may also have ligandindependent biological activity $[66,67]$.

The involvement of IGFBPs in cancer varies by the type of malignancy. For example, IGFBP-2, -3 , and -5 are associated with glioblastoma more commonly than other brain tumors and IGFBP-3 in particular is associated with shorter overall survival [68]. In breast cancer cells, IGFBP-5 is associated with metastasis [69] and poor prognosis [70]. However, the specific mechanisms by which IGFBPs affect tumor progression are complex and published data are sometimes discrepant. For instance, despite the aforementioned association between IGFBP-5 and metastasis, forced-overexpression of IGFBP-5 in breast cancer cell lines actually inhibits cell growth [71]. Further studies have determined that the subcellular localization of IGFBP-5 influences its biological effect. Indeed, cytoplasmic IGFBP-5 promotes cell proliferation and motility [72] while nuclear IGFBP-5 does not [71]. Interestingly, ligand-independent activity for IGFBP-5 [73] is thought to involve the AKT pathway with effects on ovarian cancer angiogenesis [74]. IGFBP-2 has also demonstrated ligand-independent activity, mediated by interactions with cell surface integrins [75, 76]. Another binding protein with ligand-independent activity is IGFBP-4, which physically interacts with Frz8, a Wnt receptor, in cardiomyocytes and inhibits activation by Wnt3A ligand [77]. This discovery adds to the complexity of the IGF system and previouslymentioned pathway crosstalk. However, the impact of IGFBP-4 on Wnt signaling in cancer biology remains to be characterized.

\section{Specific Cancers}

\section{Breast}

Breast cancer is the most common malignancy in American women and is the second most common cause of death due to cancer [78]. The IGF system has a presence in most solid and hematologic malignancies, including breast cancer. The extent of IGF-1R expression in breast cancer varies by methodology but may approach $90 \%$ of tumours [79]. This presents a potentially greater opportunity for targeted therapy than HER2, which is present in 20-25\% of all breast cancers. Although the prognostic value of IGF-1R expression is debatable [80, 81], in vitro studies have demonstrated that IGF-1 contributes to breast cancer growth by promoting cell proliferation and chemotherapy resistance $[82,83]$. The role of IGF-1, IGF-1R, IGFBPs, Hybrid-Rs, and IGF signaling crosstalk in breast cancer are discussed above. Targeting these crosstalk pathways in breast cancer remains an active area of clinical investigation.

\section{Sarcomas}

Genetic and cytogenetic aberrations are predominate oncogenic forces in sarcoma development and this may have downstream consequences for the IGF system. For example, Ewing's sarcoma (ES) is characterized by a $(11 ; 22)$ translocation producing the EWSR1FLI1 fusion protein, which acts as an aberrant transcription factor leading to the 
upregulation of downstream targets like c-myc [84], cyclin D1 [85], and PDGF-C [86]. IGF-1R expression is a pre-requisite to EWSR1-FLI1 mediated transformation [87], required for ES cell survival [88], and attenuates the efficacy of cytotoxic chemotherapy [89]. Inhibition of the IGF-1R with NVP-AEW541, a small molecule inhibitor, induces cell cycle arrest and apoptosis in vitro and reduces in vivo growth of ES cells [90]. A phase I single-agent clinical trial with a fully human IGF-1R monoclonal antibody inhibitor figitumumab (CP-751,871) demonstrated clinical benefit (objective response or stable disease) in 50\% ( $\mathrm{n}=16)$ of ES patients [91]. In a follow-up phase II trial with 125 ES patients with recurrent or refractory disease, objective responses where observed in $14.4 \%$ [92]. A smaller phase II trial with 35 ES or desmoplastic small round cell tumor patients demonstrated an objective response rate of $6 \%$ with single-agent AMG 479 [93]. The modest clinical responses despite strong pre-clinical data support the contention that patients should be selected based on a tumor phenotype rather than histologic classification. Moreover, the activation of parallel but interconnected signal transduction pathways in ES suggested a potential role for multi-pathway targeting of IGF-1R and mTOR [94-96].

Less is known about the IGF system in other sarcomas but interesting observations have been made that have not yet been described for carcinomas. For instance, alveolar rhabdomyosarcoma is a pediatric sarcoma characterized by a $\mathrm{t}(2 ; 13)$ translocation that results in a Pax3-FKHR fusion gene. The Pax3-FKHR fusion protein can transactivate the IGFR1 gene [97], leading to an overexpression of IGF-1R with growth and survival advantages that are abrogated by IGF-1R knockdown [98]. In gastrointestinal stromal cell tumors (GIST), KIT/platelet derived growth factor receptor (PDGFR)- $a$ wildtype tumors are less responsive to imatinib therapy and pose a therapeutic challenge [99]. This subset of GIST exhibits $I G F 1 R$ gene amplified and overexpression that drives cell growth and survival, suggesting a possible role for IGF targeting [100].

\section{Gliomas}

Gliomas are malignant central nervous tumors that include ependymomas, astrocytomas, oligodendrogliomas, and mixed gliomas. Glioblastoma multiforme (GBM) is the most common and aggressive subtype of astrocytomas. The primary treatment is surgical resection followed by chemotherapy and radiation therapy. However, prognosis remains poor and recurrence is common. Cumulative data indicates an important role for the IGF system in glioblastoma progression. For example, C6 glioblastoma cells exhibit growth inhibition when IGF-1R is down regulated in vivo and in vitro [101] and inhibition of IGF-1R by picropodophyllin(small molecule tyrosine kinase inhibitor) inhibits cell growth by reduced AKT activation [102]. The pro-survival influence of IGF-1R has been linked to increased expression of Bcl-2 [103]. GBM is known for its ability to invade the surrounding brain parenchyma as well as stimulate angiogenesis. The IGF system is implicated in this process as perivascular tumor cells express higher levels of IGF-1R [104], which is known to modulate production of VEGF [105]. In addition, treatment of glioblastoma cells with IGF-1 increases cellular migration [106]. Taken together with the observation that tumor cells within the margins of infiltration express higher levels of IGF-1R [104], the IGF system is intimately linked to glioblastoma tumor invasion. Although radiation therapy is effective in prolonging patient survival, local recurrences may actually be promoted by radiation therapy through activation of EGFR, IGF-1R, and PDGFR [107, 108], while inhibition of these pathways increases radiosensitivity [108]. An additional example of signal transduction crosstalk has been reported in GBM as IGF-1R up-regulation can induce resistance to EGFR inhibition [109]. Thus, targeting IGF signaling in gliomas may be a promising anti-cancer strategy. 


\section{Lung Cancer}

Lung cancer is the second most common malignancy afflicting American patients. While platinum-based chemotherapy may provide modest benefit for advanced disease, lung cancer remains the most common cause of cancer deaths in 2010 [78]. The IGF system has been implicated in essentially all phases of lung cancer oncogenesis. For instance, high grade bronchial dysplasia produces greater paracrine and autocrine IGF than benign bronchial epithelial cells [110], suggesting the IGF system has an early role in lung cancer development. In addition, non-small cell lung cancer (NSCLC) cells, particularly the squamous cell subtype, is associated with increased IGFIR gene copy number and mRNA/ protein expression [111], providing a growth and survival advantage to malignant cells and resistance to chemotherapy [112]. Inhibition of IGF-1R with figitumumab (anti-IGF-IR antibody) leads to downregulated receptor expression, inhibition of tumor growth [113], and radiosensitization of cancer cells [114]. Promising preclinical data and a phase I clinical trial results with figitumumab in advanced cancers [115] led to a phase II trial with combination therapy in NSCLC [116]. The objective response rate was $54 \%$ for all NSCLC subtypes but reached an impressive $78 \%$ in patients with the squamous cell subtype. Although the subsequent phase III trial with figitumumab as first-line treatment in NSCLC cancer was greatly anticipated, it was stopped early when interim analysis failed to show a benefit in the figitumumab arm [117].

\section{Ovarian}

Ovarian cancer is the fifth most common cause of death due to cancer in women [78]. Epidemiologic data has linked IGF-1R to high tumor grade and stage, and is associated with poor survival [118]. Although localized disease is associated with a 93\% 5-year survival rate, 79\% of patients are stage III or IV at the time of initial diagnosis [78]. After debulking surgery and six cycles of platinum-based chemotherapy, $75 \%$ of patients will achieve complete remission but three-quarters of them will relapse within 20 months, on average [119]. While retreatment with a platinum-based regimen is reasonable after a six month platinum-free period, resistance is common and may be attributed to increased IGF-1R expression in ovarian tumor cells [120]. Although primary ovarian tumor cell cultures do not overexpress IGF, dysregulation of IGF homeostasis by the overexpression of IGFBP-2 in ovarian cancer cells may sequester and maintain an elevated localized pool of IGF for activation of IGF-1R $[63,121]$. A phase II clinical trial is currently evaluating the efficacy and tolerability of front-line AMG-479, a fully-human monoclonal antibody against the IGF-1R, in combination with carboplatin and paclitaxel in advanced stage, optimallydebulked epithelial ovarian, primary peritoneal, and fallopian tube cancer (TRIO-014).

\section{Conclusions}

The IGF system has been implicated in the oncogenesis of essentially all solid and hematologic malignancies. The central involvement of IGF signaling in tumor cell proliferation, survival, invasion, and metastasis makes it an attractive therapeutic target. Importantly, the IGF signaling pathway has also been directly implicated in resistance to clinically important therapies, including hormonal agents, HER receptor targeting agents, radiation and cytotoxic chemotherapy. Indeed, several clinical trials are currently evaluating the efficacy of IGF-1R inhibition to either overcome these resistance mechanisms or directly induce anti-proliferative effects on tumors dependent on IGF signaling. Current strategies include monoclonal antibodies directed at IGF-1R, tyrosine kinase inhibitors with activity against IGF-1R +/- IR and anti-ligand antibodies. The optimal strategy for targeting IGF signaling in patients with cancer is not clear. The modest benefits reported thus far underscore the need for a better understanding of IGF signaling, which would enable 
clinicians to identify the subset of patients with the greatest likelihood of attaining benefit from this targeted approach.

\section{Acknowledgments}

This work was supported by the United States National Institutes of Health Grant CA136393, Mayo Clinic SPORE in Ovarian Cancer, CA116201 Mayo Clinic Breast SPORE and CA090628 K12

\section{References}

1. Baris D, et al. Acromegaly and cancer risk: a cohort study in Sweden and Denmark. Cancer Causes Control. 2002; 13(5):395-400. [PubMed: 12146843]

2. Kauppinen-Makelin R, et al. Increased cancer incidence in acromegaly--a nationwide survey. Clin Endocrinol (Oxf). 2010; 72(2):278-9. [PubMed: 19453622]

3. Orme SM, et al. Mortality and cancer incidence in acromegaly: a retrospective cohort study. United Kingdom Acromegaly Study Group. J Clin Endocrinol Metab. 1998; 83(8):2730-4. [PubMed: 9709939]

4. Ron E, et al. Acromegaly and gastrointestinal cancer. Cancer. 1991; 68(8):1673-7. [PubMed: 1913507]

5. Jenkins PJ, et al. Insulin-like growth factor I and the development of colorectal neoplasia in acromegaly. J Clin Endocrinol Metab. 2000; 85(9):3218-21. [PubMed: 10999811]

6. Key TJ, et al. Insulin-like growth factor 1 (IGF1), IGF binding protein 3 (IGFBP3), and breast cancer risk: pooled individual data analysis of 17 prospective studies. Lancet Oncol. 2010; 11(6): 530-42. [PubMed: 20472501]

7. Lukanova A, et al. Circulating levels of insulin-like growth factor-I and risk of ovarian cancer. Int $\mathbf{J}$ Cancer. 2002; 101(6):549-54. [PubMed: 12237896]

8. Renehan AG, et al. Circulating insulin-like growth factor II and colorectal adenomas. J Clin Endocrinol Metab. 2000; 85(9):3402-8. [PubMed: 10999841]

9. Renehan AG, et al. Insulin-like growth factor (IGF)-I, IGF binding protein-3, and cancer risk: systematic review and meta-regression analysis. Lancet. 2004; 363(9418):1346-53. [PubMed: 15110491]

10. Rinaldi S, et al. Serum levels of IGF-I, IGFBP-3 and colorectal cancer risk: results from the EPIC cohort, plus a meta-analysis of prospective studies. Int J Cancer. 2010; 126(7):1702-15. [PubMed: 19810099]

11. Roddam AW, et al. Insulin-like growth factors, their binding proteins, and prostate cancer risk: analysis of individual patient data from 12 prospective studies. Ann Intern Med. 2008; 149(7): 461-71. W83-8. [PubMed: 18838726]

12. Allen NE, et al. Serum insulin-like growth factor (IGF)-I and IGF-binding protein-3 concentrations and prostate cancer risk: results from the European Prospective Investigation into Cancer and Nutrition. Cancer Epidemiol Biomarkers Prev. 2007; 16(6):1121-7. [PubMed: 17548673]

13. Finne $P$, et al. Insulin-like growth factor $I$ is not a useful marker of prostate cancer in men with elevated levels of prostate-specific antigen. J Clin Endocrinol Metab. 2000; 85(8):2744-7. [PubMed: 10946875]

14. Lukanova A, et al. Prediagnostic levels of C-peptide, IGF-I, IGFBP -1, -2 and -3 and risk of endometrial cancer. Int J Cancer. 2004; 108(2):262-8. [PubMed: 14639613]

15. Mikami K, et al. Prostate cancer risk in relation to insulin-like growth factor (IGF)-I and IGFbinding protein-3: A nested case-control study in large scale cohort study in Japan. Asian Pac J Cancer Prev. 2009; 10(Suppl):57-61. [PubMed: 20553083]

16. Pham TM, et al. A nested case-control study of stomach cancer and serum insulin-like growth factor (IGF)-1, IGF-2 and IGF-binding protein (IGFBP)-3. Eur J Cancer. 2007; 43(10):1611-6. [PubMed: 17532620]

17. Sakauchi F, et al. Serum insulin-like growth factors I and II, insulin-like growth factor binding protein-3 and risk of breast cancer in the Japan Collaborative Cohort study. Asian Pac J Cancer Prev. 2009; 10(Suppl):51-5. [PubMed: 20553082] 
18. Spitz MR, et al. Serum insulin-like growth factor (IGF) and IGF-binding protein levels and risk of lung cancer: a case-control study nested in the beta-Carotene and Retinol Efficacy Trial Cohort. Cancer Epidemiol Biomarkers Prev. 2002; 11(11):1413-8. [PubMed: 12433720]

19. Suzuki S, et al. Insulin-like growth factor (IGF)-I, IGF-II, IGF binding protein-3, and risk of colorectal cancer: a nested case-control study in the Japan Collaborative Cohort study. Asian Pac J Cancer Prev. 2009; 10(Suppl):45-9. [PubMed: 20553081]

20. Renehan AG, Brennan BM. Acromegaly, growth hormone and cancer risk. Best Pract Res Clin Endocrinol Metab. 2008; 22(4):639-57. [PubMed: 18971124]

21. Svensson J, Bengtsson BA. Safety aspects of GH replacement. Eur J Endocrinol. 2009; 161(Suppl 1):S65-74. [PubMed: 19684054]

22. Shevah O, Laron Z. Patients with congenital deficiency of IGF-I seem protected from the development of malignancies: a preliminary report. Growth Horm IGF Res. 2007; 17(1):54-7. [PubMed: 17166755]

23. Lavoie JN, et al. Cyclin D1 expression is regulated positively by the p42/p44MAPK and negatively by the p38/HOGMAPK pathway. J Biol Chem. 1996; 271(34):20608-16. [PubMed: 8702807]

24. Hamelers IH, et al. Insulin-like growth factor I triggers nuclear accumulation of cyclin D1 in MCF-7S breast cancer cells. J Biol Chem. 2002; 277(49):47645-52. [PubMed: 12364325]

25. Mairet-Coello G, Tury A, DiCicco-Bloom E. Insulin-like growth factor-1 promotes G(1)/S cell cycle progression through bidirectional regulation of cyclins and cyclin-dependent kinase inhibitors via the phosphatidylinositol 3-kinase/Akt pathway in developing rat cerebral cortex. $\mathrm{J}$ Neurosci. 2009; 29(3):775-88. [PubMed: 19158303]

26. Ma J, et al. IGF-1 mediates PTEN suppression and enhances cell invasion and proliferation via activation of the IGF-1/PI3K/Akt signaling pathway in pancreatic cancer cells. J Surg Res. 2010; 160(1):90-101. [PubMed: 19560785]

27. Strange R, et al. Apoptosis in normal and neoplastic mammary gland development. Microsc Res Tech. 2001; 52(2):171-81. [PubMed: 11169865]

28. Sun Y. Oxidative stress and cardiac repair/remodeling following infarction. Am J Med Sci. 2007; 334(3):197-205. [PubMed: 17873534]

29. Datta SR, et al. Akt phosphorylation of BAD couples survival signals to the cell-intrinsic death machinery. Cell. 1997; 91(2):231-41. [PubMed: 9346240]

30. Brunet A, et al. Akt promotes cell survival by phosphorylating and inhibiting a Forkhead transcription factor. Cell. 1999; 96(6):857-68. [PubMed: 10102273]

31. Kane LP, et al. Induction of NF-kappaB by the Akt/PKB kinase. Curr Biol. 1999; 9(11):601-4. [PubMed: 10359702]

32. Mayo LD, Donner DB. A phosphatidylinositol 3-kinase/Akt pathway promotes translocation of Mdm2 from the cytoplasm to the nucleus. Proc Natl Acad Sci U S A. 2001; 98(20):11598-603. [PubMed: 11504915]

33. Zhang D, Brodt P. Type 1 insulin-like growth factor regulates MT1-MMP synthesis and tumor invasion via PI 3-kinase/Akt signaling. Oncogene. 2003; 22(7):974-82. [PubMed: 12592384]

34. Ullrich A, et al. Insulin-like growth factor I receptor primary structure: comparison with insulin receptor suggests structural determinants that define functional specificity. EMBO J. 1986; 5(10): 2503-12. [PubMed: 2877871]

35. Moller DE, et al. Tissue-specific expression of two alternatively spliced insulin receptor mRNAs in man. Mol Endocrinol. 1989; 3(8):1263-9. [PubMed: 2779582]

36. Frasca F, et al. Insulin receptor isoform A, a newly recognized, high-affinity insulin-like growth factor II receptor in fetal and cancer cells. Mol Cell Biol. 1999; 19(5):3278-88. [PubMed: 10207053]

37. Kido Y, Nakae J, Accili D. Clinical review 125: The insulin receptor and its cellular targets. J Clin Endocrinol Metab. 2001; 86(3):972-9. [PubMed: 11238471]

38. Papa V, et al. Elevated insulin receptor content in human breast cancer. J Clin Invest. 1990; 86(5): 1503-10. [PubMed: 2243127]

39. Kalli KR, et al. Functional insulin receptors on human epithelial ovarian carcinoma cells: implications for IGF-II mitogenic signaling. Endocrinology. 2002; 143(9):3259-67. [PubMed: 12193537] 
40. Mathieu MC, et al. Insulin receptor expression and clinical outcome in node-negative breast cancer. Proc Assoc Am Physicians. 1997; 109(6):565-71. [PubMed: 9394418]

41. Belfiore A, et al. Insulin/IGF-I hybrid receptors play a major role in IGF-I signaling in thyroid cancer. Biochimie. 1999; 81(4):403-7. [PubMed: 10401676]

42. Garrouste FL, et al. Up-regulation of insulin/insulin-like growth factor-I hybrid receptors during differentiation of HT29-D4 human colonic carcinoma cells. Endocrinology. 1997; 138(5):202132. [PubMed: 9112401]

43. Pandini G, et al. Insulin/insulin-like growth factor I hybrid receptors have different biological characteristics depending on the insulin receptor isoform involved. J Biol Chem. 2002; 277(42): 39684-95. [PubMed: 12138094]

44. Benyoucef S, et al. Characterization of insulin/IGF hybrid receptors: contributions of the insulin receptor L2 and Fn1 domains and the alternatively spliced exon 11 sequence to ligand binding and receptor activation. Biochem J. 2007; 403(3):603-13. [PubMed: 17291192]

45. Slaaby R, et al. Hybrid receptors formed by insulin receptor (IR) and insulin-like growth factor I receptor (IGF-IR) have low insulin and high IGF-1 affinity irrespective of the IR splice variant. J Biol Chem. 2006; 281(36):25869-74. [PubMed: 16831875]

46. Pandini G, et al. Functional responses and in vivo anti-tumour activity of h7C10: a humanised monoclonal antibody with neutralising activity against the insulin-like growth factor-1 (IGF-1) receptor and insulin/IGF-1 hybrid receptors. Eur J Cancer. 2007; 43(8):1318-27. [PubMed: 17451939]

47. Jenab M, et al. Serum C-peptide, IGFBP-1 and IGFBP-2 and risk of colon and rectal cancers in the European Prospective Investigation into Cancer and Nutrition. Int J Cancer. 2007; 121(2):368-76. [PubMed: 17372899]

48. Haluska $P$, et al. HER receptor signaling confers resistance to the insulin-like growth factor-I receptor inhibitor, BMS-536924. Mol Cancer Ther. 2008; 7(9):2589-98. [PubMed: 18765823]

49. Knowlden JM, et al. Insulin receptor substrate-1 involvement in epidermal growth factor receptor and insulin-like growth factor receptor signalling: implication for Gefitinib ('Iressa') response and resistance. Breast Cancer Res Treat. 2008; 111(1):79-91. [PubMed: 17902048]

50. Vogel CL, et al. Efficacy and safety of trastuzumab as a single agent in first-line treatment of HER2-overexpressing metastatic breast cancer. J Clin Oncol. 2002; 20(3):719-26. [PubMed: $11821453]$

51. Lu Y, et al. Insulin-like growth factor-I receptor signaling and resistance to trastuzumab (Herceptin). J Natl Cancer Inst. 2001; 93(24):1852-7. [PubMed: 11752009]

52. Nahta R, et al. Insulin-like growth factor-I receptor/human epidermal growth factor receptor 2 heterodimerization contributes to trastuzumab resistance of breast cancer cells. Cancer Res. 2005; 65(23):11118-28. [PubMed: 16322262]

53. Morgillo F, et al. Heterodimerization of insulin-like growth factor receptor/epidermal growth factor receptor and induction of survivin expression counteract the antitumor action of erlotinib. Cancer Res. 2006; 66(20):10100-11. [PubMed: 17047074]

54. Campbell RA, et al. Phosphatidylinositol 3-kinase/AKT-mediated activation of estrogen receptor alpha: a new model for anti-estrogen resistance. J Biol Chem. 2001; 276(13):9817-24. [PubMed: 11139588]

55. Massarweh S, et al. Tamoxifen resistance in breast tumors is driven by growth factor receptor signaling with repression of classic estrogen receptor genomic function. Cancer Res. 2008; 68(3): 826-33. [PubMed: 18245484]

56. Shah OJ, Wang Z, Hunter T. Inappropriate activation of the TSC/Rheb/mTOR/S6K cassette induces IRS1/2 depletion, insulin resistance, and cell survival deficiencies. Curr Biol. 2004; 14(18):1650-6. [PubMed: 15380067]

57. Sarbassov DD, et al. Phosphorylation and regulation of Akt/PKB by the rictor-mTOR complex. Science. 2005; 307(5712):1098-101. [PubMed: 15718470]

58. Huang J, Manning BD. A complex interplay between Akt, TSC2 and the two mTOR complexes. Biochem Soc Trans. 2009; 37(Pt 1):217-22. [PubMed: 19143635]

59. Haluska P, et al. N0733: Phase II trial of capecitabine and lapatinib plus or minus cixutumumab in HER2-positive breast cancer. ASCO Meeting Abstracts. 2010; 28(15_suppl):TPS129. 
60. Reidy DL, et al. Randomized, phase II study of the insulin-like growth factor-1 receptor inhibitor IMC-A12, with or without cetuximab, in patients with cetuximab- or panitumumab-refractory metastatic colorectal cancer. J Clin Oncol. 2010; 28(27):4240-6. [PubMed: 20713879]

61. Di Cosimo S, et al. A phase I study of the oral mTOR inhibitor ridaforolimus (RIDA) in combination with the IGF-1R antibody dalotozumab (DALO) in patients (pts) with advanced solid tumors. ASCO Meeting Abstracts. 2010; 28(15_suppl):3008.

62. Shimasaki S, Ling N. Identification and molecular characterization of insulin-like growth factor binding proteins (IGFBP-1, -2, -3, -4, -5 and -6). Prog Growth Factor Res. 1991; 3(4):243-66. [PubMed: 1725860]

63. Wang $\mathrm{H}$, et al. Insulin-like growth factor-binding protein 2 and 5 are differentially regulated in ovarian cancer of different histologic types. Mod Pathol. 2006; 19(9):1149-56. [PubMed: 16729015]

64. Jaques G, et al. Nuclear localization of insulin-like growth factor binding protein 3 in a lung cancer cell line. Endocrinology. 1997; 138(4):1767-70. [PubMed: 9075742]

65. Schedlich LJ, et al. Insulin-like growth factor-binding protein (IGFBP)-3 and IGFBP-5 share a common nuclear transport pathway in T47D human breast carcinoma cells. J Biol Chem. 1998; 273(29):18347-52. [PubMed: 9660801]

66. Laursen LS, et al. Regulation of insulin-like growth factor (IGF) bioactivity by sequential proteolytic cleavage of IGF binding protein-4 and -5. Mol Endocrinol. 2007; 21(5):1246-57. [PubMed: 17312271]

67. Lalou C, Lassarre C, Binoux M. A proteolytic fragment of insulin-like growth factor (IGF) binding protein-3 that fails to bind IGFs inhibits the mitogenic effects of IGF-I and insulin. Endocrinology. 1996; 137(8):3206-12. [PubMed: 8754741]

68. Santosh V, et al. Grade-specific expression of insulin-like growth factor-binding proteins-2, -3 , and -5 in astrocytomas: IGFBP-3 emerges as a strong predictor of survival in patients with newly diagnosed glioblastoma. Cancer Epidemiol Biomarkers Prev. 2010; 19(6):1399-408. [PubMed: 20501753]

69. Wang H, et al. IGFBP2 and IGFBP5 overexpression correlates with the lymph node metastasis in T1 breast carcinomas. Breast J. 2008; 14(3):261-7. [PubMed: 18373644]

70. Mita K, et al. Prognostic significance of insulin-like growth factor binding protein (IGFBP)-4 and IGFBP-5 expression in breast cancer. Jpn J Clin Oncol. 2007; 37(8):575-82. [PubMed: 17675285]

71. Butt AJ, et al. Insulin-like growth factor-binding protein-5 inhibits the growth of human breast cancer cells in vitro and in vivo. J Biol Chem. 2003; 278(32):29676-85. [PubMed: 12777377]

72. Akkiprik M, et al. The subcellular localization of IGFBP5 affects its cell growth and migration functions in breast cancer. BMC Cancer. 2009; 9:103. [PubMed: 19341485]

73. Tripathi G, et al. IGF-independent effects of insulin-like growth factor binding protein-5 (Igfbp5) in vivo. FASEB J. 2009; 23(8):2616-26. [PubMed: 19332648]

74. Rho SB, et al. Insulin-like growth factor-binding protein-5 (IGFBP-5) acts as a tumor suppressor by inhibiting angiogenesis. Carcinogenesis. 2008; 29(11):2106-11. [PubMed: 18775916]

75. Schutt BS, et al. Integrin-mediated action of insulin-like growth factor binding protein-2 in tumor cells. J Mol Endocrinol. 2004; 32(3):859-68. [PubMed: 15171717]

76. Wang GK, et al. An interaction between insulin-like growth factor-binding protein 2 (IGFBP2) and integrin alpha5 is essential for IGFBP2-induced cell mobility. J Biol Chem. 2006; 281(20):1408591. [PubMed: 16569642]

77. Zhu W, et al. IGFBP-4 is an inhibitor of canonical Wnt signalling required for cardiogenesis. Nature. 2008; 454(7202):345-9. [PubMed: 18528331]

78. Jemal A, et al. Cancer Statistics, 2010. CA Cancer J Clin. 2010

79. Peyrat JP, et al. Insulin-like growth factor 1 receptors (IGF1-R) and IGF1 in human breast tumors. J Steroid Biochem Mol Biol. 1990; 37(6):823-7. [PubMed: 2178365]

80. Railo MJ, von Smitten K, Pekonen F. The prognostic value of insulin-like growth factor-I in breast cancer patients. Results of a follow-up study on 126 patients. Eur J Cancer. 1994; 30A(3):307-11. [PubMed: 8204350]

81. Papa V, et al. Insulin-like growth factor-I receptors are overexpressed and predict a low risk in human breast cancer. Cancer Res. 1993; 53(16):3736-40. [PubMed: 8339284] 
82. Dunn SE, et al. Insulin-like growth factor 1 (IGF-1) alters drug sensitivity of HBL100 human breast cancer cells by inhibition of apoptosis induced by diverse anticancer drugs. Cancer Res. 1997; 57(13):2687-93. [PubMed: 9205078]

83. Gooch JL, Van Den Berg CL, Yee D. Insulin-like growth factor (IGF)-I rescues breast cancer cells from chemotherapy-induced cell death--proliferative and anti-apoptotic effects. Breast Cancer Res Treat. 1999; 56(1):1-10. [PubMed: 10517338]

84. Bailly RA, et al. DNA-binding and transcriptional activation properties of the EWS-FLI-1 fusion protein resulting from the $\mathrm{t}(11 ; 22)$ translocation in Ewing sarcoma. Mol Cell Biol. 1994; 14(5): 3230-3241. [PubMed: 8164678]

85. Matsumoto Y, et al. Downregulation and forced expression of EWS-Fli1 fusion gene results in changes in the expression of G(1)regulatory genes. Br J Cancer. 2001; 84(6):768-75. [PubMed: 11259090]

86. Zwerner JP, May WA. PDGF-C is an EWS/FLI induced transforming growth factor in Ewing family tumors. Oncogene. 2001; 20(5):626-33. [PubMed: 11313995]

87. Toretsky JA, et al. The insulin-like growth factor-I receptor is required for EWS/FLI-1 transformation of fibroblasts. J Biol Chem. 1997; 272(49):30822-7. [PubMed: 9388225]

88. Yee D, et al. Insulin-like growth factor I expression by tumors of neuroectodermal origin with the $\mathrm{t}(11 ; 22)$ chromosomal translocation. A potential autocrine growth factor. J Clin Invest. 1990; 86(6):1806-14. [PubMed: 2174908]

89. Benini S, et al. Inhibition of insulin-like growth factor I receptor increases the antitumor activity of doxorubicin and vincristine against Ewing's sarcoma cells. Clin Cancer Res. 2001; 7(6):1790-7. [PubMed: 11410521]

90. Scotlandi K, et al. Antitumor activity of the insulin-like growth factor-I receptor kinase inhibitor NVP-AEW541 in musculoskeletal tumors. Cancer Res. 2005; 65(9):3868-76. [PubMed: 15867386]

91. Olmos D, et al. Safety, pharmacokinetics, and preliminary activity of the anti-IGF-1R antibody figitumumab (CP-751,871) in patients with sarcoma and Ewing's sarcoma: a phase 1 expansion cohort study. Lancet Oncol. 2010; 11(2):129-35. [PubMed: 20036194]

92. Pappo AS, et al. Activity of R1507, a monoclonal antibody to the insulin-like growth factor-1 receptor (IGF1R), in patients (pts) with recurrent or refractory Ewing's sarcoma family of tumors (ESFT): Results of a phase II SARC study. ASCO Meeting Abstracts. 2010; 28(15_suppl):10000.

93. Tap WD, et al. AMG 479 in relapsed or refractory Ewing's family tumors (EFT) or desmoplastic small round cell tumors (DSRCT): Phase II results. ASCO Meeting Abstracts. 2010; 28(15_suppl): 10001.

94. Krishnan K, et al. Ezrin mediates growth and survival in Ewing's sarcoma through the AKT/ mTOR, but not the MAPK, signaling pathway. Clin Exp Metastasis. 2006; 23(3-4):227-36. [PubMed: 17028919]

95. Benini S, et al. Contribution of MEK/MAPK and PI3-K signaling pathway to the malignant behavior of Ewing's sarcoma cells: therapeutic prospects. Int J Cancer. 2004; 108(3):358-66. [PubMed: 14648701]

96. van de Luijtgaarden AC, et al. Predicting an optimal strategy for insulin-like growth factor 1 (IGF1) signaling interference in Ewing's sarcoma (ES). ASCO Meeting Abstracts. 2010; 28(15_suppl):9538.

97. Ayalon D, Glaser T, Werner H. Transcriptional regulation of IGF-I receptor gene expression by the PAX3-FKHR oncoprotein. Growth Horm IGF Res. 2001; 11(5):289-97. [PubMed: 11735247]

98. Shapiro DN, et al. Antisense-mediated reduction in insulin-like growth factor-I receptor expression suppresses the malignant phenotype of a human alveolar rhabdomyosarcoma. J Clin Invest. 1994; 94(3):1235-42. [PubMed: 8083365]

99. Debiec-Rychter M, et al. Use of c-KIT/PDGFRA mutational analysis to predict the clinical response to imatinib in patients with advanced gastrointestinal stromal tumours entered on phase I and II studies of the EORTC Soft Tissue and Bone Sarcoma Group. Eur J Cancer. 2004; 40(5): 689-95. [PubMed: 15010069] 
100. Tarn C, et al. Insulin-like growth factor 1 receptor is a potential therapeutic target for gastrointestinal stromal tumors. Proc Natl Acad Sci U S A. 2008; 105(24):8387-92. [PubMed: 18550829]

101. Resnicoff M, et al. Rat glioblastoma cells expressing an antisense RNA to the insulin-like growth factor-1 (IGF-1) receptor are nontumorigenic and induce regression of wild-type tumors. Cancer Res. 1994; 54(8):2218-22. [PubMed: 8174129]

102. Yin S, et al. Targeting the insulin-like growth factor-1 receptor by picropodophyllin as a treatment option for glioblastoma. Neuro Oncol. 2010; 12(1):19-27. [PubMed: 20150364]

103. Yin D, et al. Insulin-like growth factor-I decreased etoposide-induced apoptosis in glioma cells by increasing bcl-2 expression and decreasing CPP32 activity. Neurol Res. 2005; 27(1):27-35. [PubMed: 15829155]

104. Hirano $\mathrm{H}$, et al. Insulin-like growth factor-1 content and pattern of expression correlates with histopathologic grade in diffusely infiltrating astrocytomas. Neuro Oncol. 1999; 1(2):109-19. [PubMed: 11550306]

105. Gariboldi MB, Ravizza R, Monti E. The IGFR1 inhibitor NVP-AEW541 disrupts a pro-survival and pro-angiogenic IGF-STAT3-HIF1 pathway in human glioblastoma cells. Biochem Pharmacol. 2010; 80(4):455-62. [PubMed: 20488164]

106. Schlenska-Lange A, et al. Cell proliferation and migration in glioblastoma multiforme cell lines are influenced by insulin-like growth factor I in vitro. Anticancer Res. 2008; 28(2A):1055-60. [PubMed: 18507054]

107. Zhai GG, et al. Radiation enhances the invasive potential of primary glioblastoma cells via activation of the Rho signaling pathway. J Neurooncol. 2006; 76(3):227-37. [PubMed: 16200346]

108. Carapancea M, et al. Dual targeting of IGF-1R and PDGFR inhibits proliferation in high-grade gliomas cells and induces radiosensitivity in JNK-1 expressing cells. J Neurooncol. 2007; 85(3): 245-54. [PubMed: 17568996]

109. Chakravarti A, Loeffler JS, Dyson NJ. Insulin-like growth factor receptor I mediates resistance to anti-epidermal growth factor receptor therapy in primary human glioblastoma cells through continued activation of phosphoinositide 3-kinase signaling. Cancer Res. 2002; 62(1):200-7. [PubMed: 11782378]

110. Kim WY, et al. Elevated epithelial insulin-like growth factor expression is a risk factor for lung cancer development. Cancer Res. 2009; 69(18):7439-48. [PubMed: 19738076]

111. Dziadziuszko R, et al. Insulin-like Growth Factor Receptor 1 (IGF1R) Gene Copy Number Is Associated With Survival in Operable Non-Small-Cell Lung Cancer: A Comparison Between IGF1R Fluorescent In Situ Hybridization, Protein Expression, and mRNA Expression. Journal of Clinical Oncology. 2010; 28(13):2174-2180. [PubMed: 20351332]

112. Lee YJ, et al. Adenovirus expressing shRNA to IGF-1R enhances the chemosensitivity of lung cancer cell lines by blocking IGF-1 pathway. Lung Cancer. 2007; 55(3):279-86. [PubMed: 17134788]

113. Cohen BD, et al. Combination therapy enhances the inhibition of tumor growth with the fully human anti-type 1 insulin-like growth factor receptor monoclonal antibody CP-751,871. Clin Cancer Res. 2005; 11(5):2063-73. [PubMed: 15756033]

114. Iwasa $\mathrm{T}$, et al. Inhibition of insulin-like growth factor 1 receptor by CP-751,871 radiosensitizes non-small cell lung cancer cells. Clin Cancer Res. 2009; 15(16):5117-25. [PubMed: 19671857]

115. Karp DD, et al. Safety, pharmacokinetics, and pharmacodynamics of the insulin-like growth factor type 1 receptor inhibitor figitumumab (CP-751,871) in combination with paclitaxel and carboplatin. J Thorac Oncol. 2009; 4(11):1397-403. [PubMed: 19745765]

116. Karp DD, et al. Phase II Study of the Anti-Insulin-Like Growth Factor Type 1 Receptor Antibody CP-751,871 in Combination With Paclitaxel and Carboplatin in Previously Untreated, Locally Advanced, or Metastatic Non-Small-Cell Lung Cancer. Journal of Clinical Oncology. 2009; 27(15):2516-2522. [PubMed: 19380445]

117. Jassem J, et al. Randomized, open label, phase III trial of figitumumab in combination with paclitaxel and carboplatin versus paclitaxel and carboplatin in patients with non-small cell lung cancer (NSCLC). ASCO Meeting Abstracts. 2010; 28(15_suppl):7500. 
118. Sayer RA, et al. High insulin-like growth factor-2 (IGF-2) gene expression is an independent predictor of poor survival for patients with advanced stage serous epithelial ovarian cancer. Gynecol Oncol. 2005; 96(2):355-61. [PubMed: 15661221]

119. Ozols RF. Treatment goals in ovarian cancer. Int J Gynecol Cancer. 2005; 15(Suppl 1):3-11. [PubMed: 15839952]

120. Eckstein N, et al. Hyperactivation of the insulin-like growth factor receptor I signaling pathway is an essential event for cisplatin resistance of ovarian cancer cells. Cancer Res. 2009; 69(7):29963003. [PubMed: 19318572]

121. Conover CA, et al. Biological characterization of human epithelial ovarian carcinoma cells in primary culture: the insulin-like growth factor system. Exp Cell Res. 1998; 238(2):439-49. [PubMed: 9473353] 

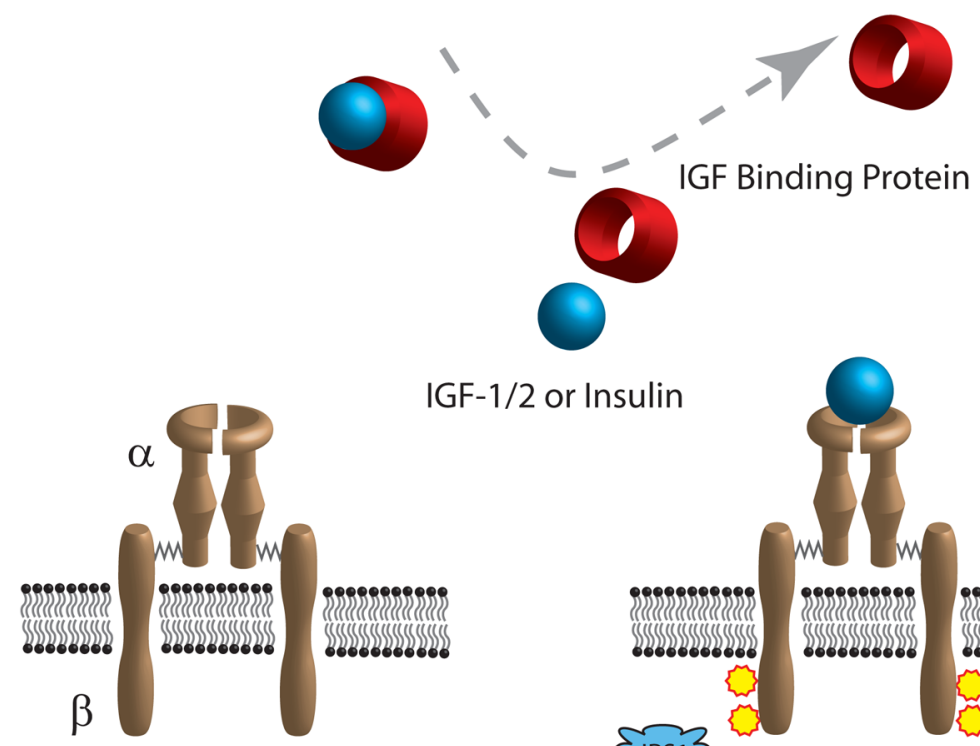

GF-1/2 or Insulin

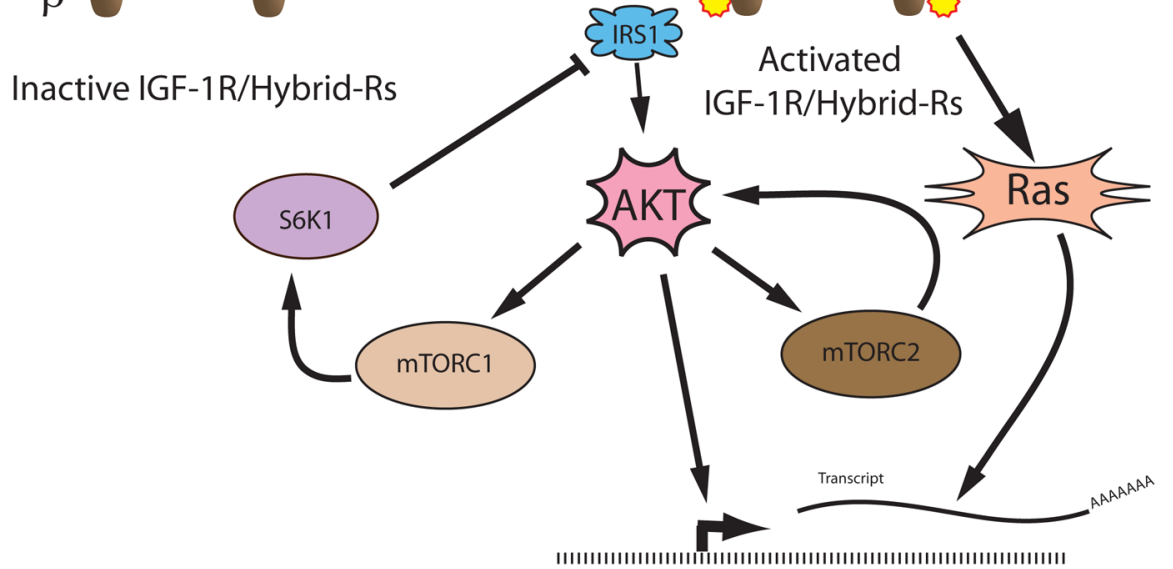

Target genes

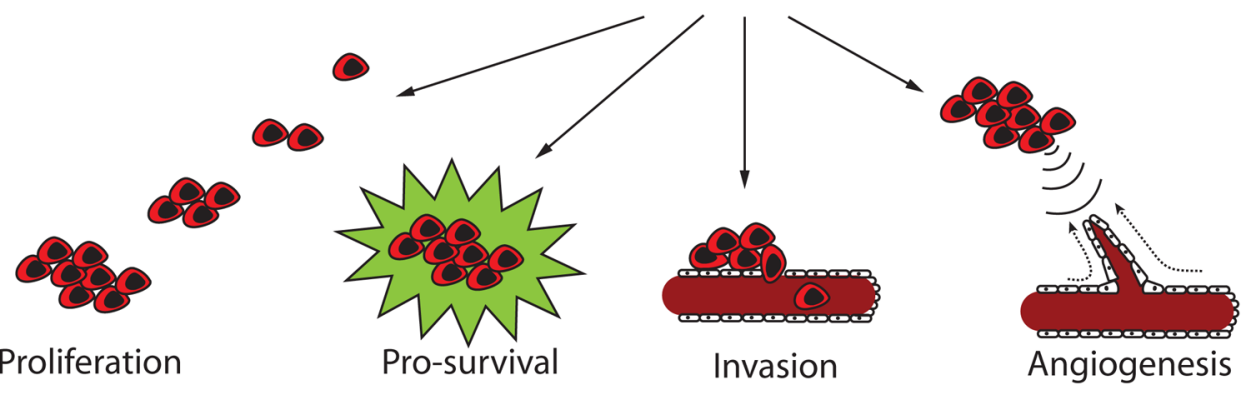

Figure 1.

Circulating IGF-1/2 is bound to IGF binding proteins and released at the IGF-1R, which is comprised of an alpha and beta tetrameric receptor. This leads to the activation of Ras and AKT with subsequent upregulation of genes involved in cell proliferation, survival, invasion, and angiogenesis. AKT is also an upstream regulator of mTORC1 and downstream effector of mTORC2. Both mTOR complexes play an important role in positive and negative feedback on the IGF/AKT signaling pathway.

Legend: Insulin like growth factor (IGF), IGF receptor 1 (IGF-1R), Hybrid receptors (Hybrid-Rs), insulin receptor substrate 1 (IRS1), mammalian target of rapamycin complex (mTORC), p70 S6 kinase (S6K1). 


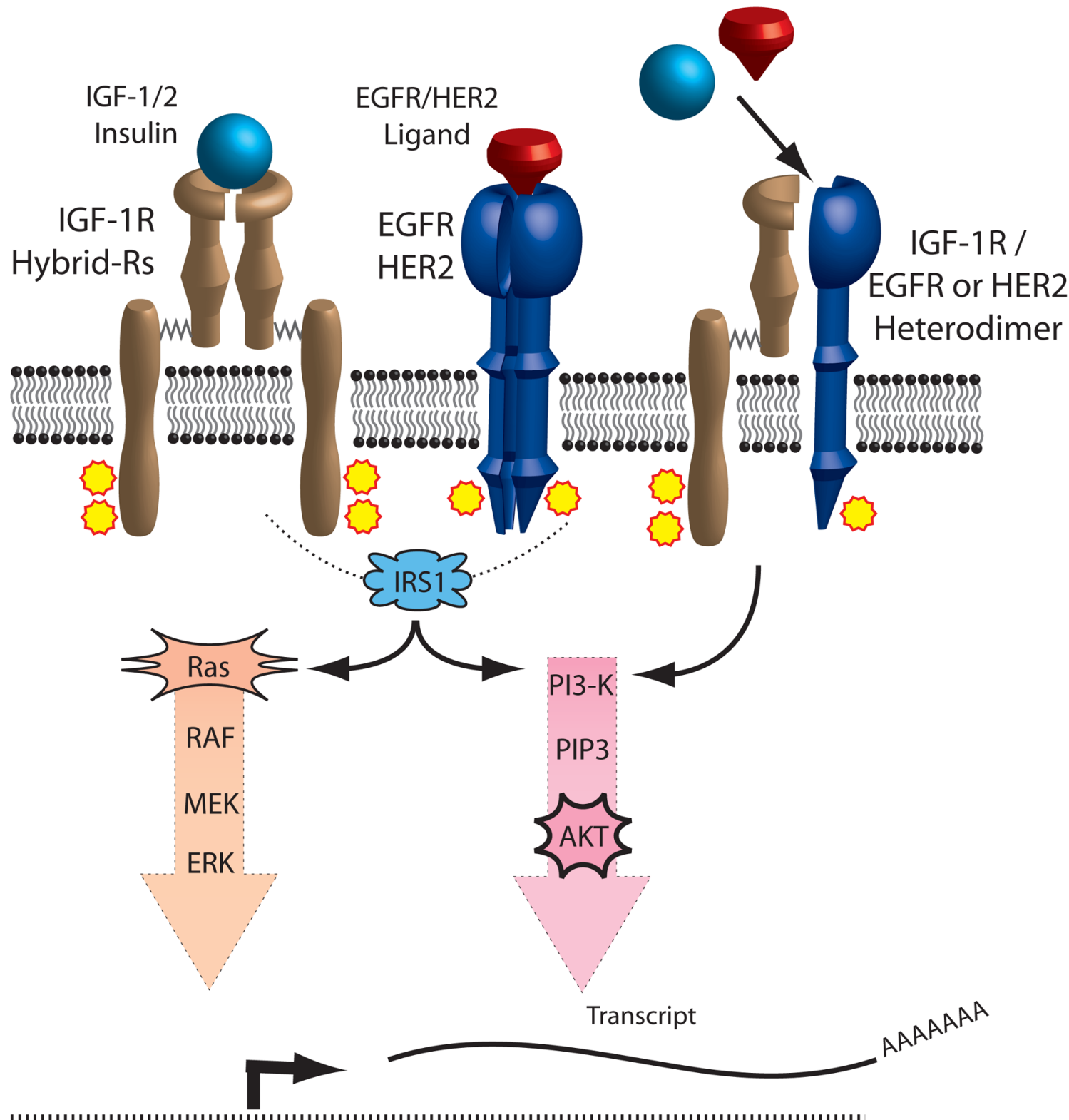

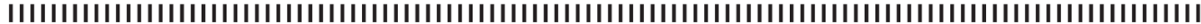

\section{Target genes}

Figure 2.

IGF-1R and EGFR/HER2crosstalk occurs by two main mechanisms. Since both pathways share a common signal transduction mediator, IRS1, resistance to inhibition of one receptor pathway can result from activation of IRS1 by the alternate receptor pathway. In addition, the formation of IGF-1R and EGFR/HER2 heterodimers increases the functional pool of receptors capable of binding IGF or EGFR/HER2 ligands, thus conferring resistance to single-agent targeted therapy.

Legend: Insulin like growth factor (IGF), IGF receptor 1 (IGF-1R), Hybrid receptors (Hybrid-Rs), epidermal growth factor receptor (EGFR), human epidermal growth factor receptor 2 (HER2), insulin receptor substrate 1 (IRS1), phosphatidylinositol 3-kinase (PI3K) 